University of Wollongong

Research Online

Faculty of Engineering and Information

Faculty of Engineering and Information

Sciences - Papers: Part A

Sciences

$1-1-2013$

\title{
Estimation of capacity credits for wind generation plants in the South East Australian power grid
}

Md Abu Abdullah

University of Wollongong, maa267@uowmail.edu.au

Kashem Muttaqi

University of Wollongong, kashem@uow.edu.au

Ashish Agalgaonkar

University of Wollongong, ashish@uow.edu.au

Darmawan Sutanto

University of Wollongong, soetanto@uow.edu.au

Follow this and additional works at: https://ro.uow.edu.au/eispapers

Part of the Engineering Commons, and the Science and Technology Studies Commons

Research Online is the open access institutional repository for the University of Wollongong. For further information contact the UOW Library: research-pubs@uow.edu.au 


\title{
Estimation of capacity credits for wind generation plants in the South East Australian power grid
}

\author{
Abstract \\ It is important to estimate the contribution of the wind generation plants in the evaluation of system \\ generation adequacy for power generation planning. Australia has recently proposed to utilize the \\ diversity of the wind energy resources in Southeast Australian power grid through existing inter-State \\ interconnections. This paper aims to present a probabilistic adequacy model for the capacity credit \\ estimation of wind generation plants in interconnected power systems. In particular, the proposed \\ adequacy model will be applied to investigate how sharing of wind energy resource diversity can enhance \\ the capacity credit of the wind generation plants. The impact of the inter-tie rating and varying wind \\ penetration on the estimated capacity credit of the shared wind generation plants is also investigated. \\ The capacity credits of the wind generation plants in each State are estimated within the purview of \\ National Electricity Market (NEM) framework of Australia. The results obtained from simulations are \\ presented and discussed.

\section{Keywords} \\ generation, plants, south, east, capacity, australian, credits, power, grid, estimation, wind

\section{Disciplines} \\ Engineering | Science and Technology Studies

\section{Publication Details} \\ M. A. Abdullah, K. M. Muttaqi, A. P. Agalgaonkar \& D. Sutanto, "Estimation of capacity credits for wind \\ generation plants in the South East Australian power grid," in Renewable Power Generation Conference \\ (RPG 2013), 2nd IET, 2013, pp. 1-4.
}




\title{
ESTIMATION OF CAPACITY CREDITS FOR WIND GENERATION PLANTS IN THE SOUTH EAST AUSTRALIAN POWER GRID
}

\author{
M.A. Abdullah, K.M. Muttaqi, A.P. Agalgaonkar, D. Sutanto \\ Endeavour Energy Power Quality and Reliability Centre, School of Electrical, Computer and Telecommunications \\ Engineering, University of Wollongong, NSW 2522, Australia.
}

Keywords: Capacity credit, interconnected power systems, generation adequacy, wind resource diversity.

\begin{abstract}
It is important to estimate the contribution of the wind generation plants in the evaluation of system generation adequacy for power generation planning. Australia has recently proposed to utilize the diversity of the wind energy resources in Southeast Australian power grid through existing inter-State interconnections. This paper aims to present a probabilistic adequacy model for the capacity credit estimation of wind generation plants in interconnected power systems. In particular, the proposed adequacy model will be applied to investigate how sharing of wind energy resource diversity can enhance the capacity credit of the wind generation plants. The impact of the inter-tie rating and varying wind penetration on the estimated capacity credit of the shared wind generation plants is also investigated. The capacity credits of the wind generation plants in each State are estimated within the purview of National Electricity Market (NEM) framework of Australia. The results obtained from simulations are presented and discussed.
\end{abstract}

\section{Introduction}

Wind energy is a promising alternative for meeting the renewable energy targets set by the energy regulatory authorities of different countries all over the world. Wind energy generation systems are usually considered as energy resources rather than capacity resources due to their variable and unpredictable characteristics. Capacity resources can be made available for generation of power to satisfy load demand. The energy resource generates a certain amount of energy over a long period of time however the availability of the generation system is not assured for a shorter time period. Since traditional generation planning methods focus on reliability and capacity planning, an increasing penetration of energy resources in power systems imposes challenges to balance the overall system demand and the available generation. Capacity credit metric quantifies the contribution of intermittent generation plants in the generation adequacy.

The uncertainty in wind generation availability during the peak demand periods and low capacity factor are the two important factors for wind generation systems to be less reliable generation source compared to the conventional generation. As a result, the wind generation systems are not receiving adequate capacity credits and hence the penetration of wind generation in the overall generation mix is not increasing significantly. Moreover, the incremental reliability benefit provided by wind generation in a typical power system reduces as the penetration of the wind generation increases. This is due to the negative or poor correlation between energy demand and wind generations [5]. Another barrier for the growth of wind generation in a power system is the scarcity of wind resources.

The geographical diversity between energy demand and wind generation can be utilised to enhance the penetration of wind generation systems. The deregulated electricity market environment and largely interconnected networks with multiple generating resources can be some of the contributory factors in maximising the utilisation of geographical diversity between energy demand and wind generation. Hence the reliability benefit and capacity credit contribution from wind generation systems can be improved in largely interconnected networks through the conduction of wind generation, wherever available in the grid, to the power system which exhibits high correlation of such generation with the local demand.

In this paper, a wind generation planning framework has been proposed for Southeast Australian power grid to share diverse wind resources from different States through existing tie-line interconnections. The capacity credits of the wind generation plants have been estimated for different State owned power networks located within Southeast Australian power grid. The reliability based index in the form of the effective load carrying capability (ELCC) of the wind generation system is used for the capacity credit estimation of the wind generation plants.

\section{Energy and demand diversity within Southeast Australian power grid}

National Electricity Market (NEM) operations in Southeast Australia are associated with the interconnected power systems of five States namely Queensland (QLD), New South Wales (NSW), Tasmania (TAS), Victoria (VIC) and South Australia (SA) as shown in Fig 1 [1]. The power transfer 
capacities of the interconnections between neighbouring power systems are indicated by the numbers above the directional arrows. The peak demand, the conventional generation capacities and the installed capacities of the wind generation systems in each power system are shown in Table 1. The electricity markets are operated independently and the neighbouring power systems actively take part in the electricity market of each other according to the NEM policy. This accessibility to neighbouring electricity markets enables the interstate renewable generations to be shared.

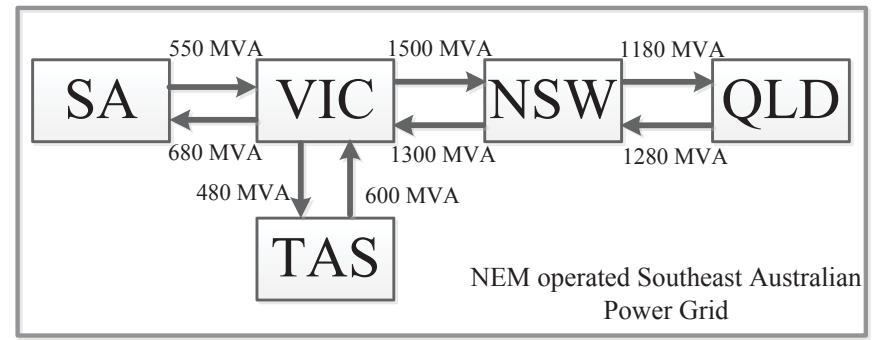

Figure 1: Interconnected power systems in Australian National Electricity Market (NEM).

\begin{tabular}{|l|c|c|c|c|c|}
\hline & SA & TAS & VIC & NSW & QLD \\
\hline Peak Demand (MVA) & 3321 & 1670 & 10366 & 14074 & 8782 \\
\hline $\begin{array}{l}\text { Conventional } \\
\text { Generation Capacity } \\
\text { (MVA) }\end{array}$ & 3799 & 3078 & 10675 & 18325 & 13637 \\
\hline $\begin{array}{l}\text { Wind Generation } \\
\text { Capacity (MVA) }\end{array}$ & 1344.1 & 140 & 860 & 265.8 & 0 \\
\hline
\end{tabular}

Table 1: NEM demand and generation data for each state.

A renewable energy target (RET) of $20 \%$ electric energy from renewable sources by 2020 has been set by the Australian government and the wind generation system is expected to serve major share of the RET [4]. SA, VIC and TAS possess most of the high wind potential locations whereas NSW and QLD have only a few high wind potential locations [4]. Hence the States having high wind resources can achieve their RET through wind generation system and the States with less wind resources will not be able to meet their RET through their own wind generation. However, it is apparent from Table 1 that the energy demands of the States with less wind resources are greater than the energy demand of the States with strong wind resources. Moreover, the poor correlation between energy demand and wind generation of a State limits the penetration of the wind generation [5]. For example, the RET of the Southeast Australian NEM cannot be achieved when assessed using traditional reliability and capacity based generation planning strategies.

However, there are diversities among the wind generations at different geographical locations and also in the correlation between wind generation and energy demand across different State owned power systems. The statistical correlation coefficients between wind generation and demand at different power systems are shown in Table 2 . It can be observed from Table 2 that the wind generation in each power system, excluding TAS, has a higher correlation with the demand of other power systems. Further, diversity exists among energy demands of the power systems within the NEM operations, which is observed from the correlation coefficients between demands of the power systems in the NEM as presented in Table 3. Table 3 shows that the energy demand in TAS has the lowest correlation with the energy demands of the rest of the power systems in the NEM. Hence the diversity of the wind generation and demand between the interconnected power systems and a deregulated electricity market operation can be utilised in the generation planning strategy towards achieving the RET.

The wind power generated in a power system containing high penetration of wind resources can be transmitted through tieline interconnections to a neighbouring power system with low penetration of wind resources to better contribute towards reliability improvements. In order to assess the impact of wind generation and energy demand diversity in the proposed generation planning, the capacity contribution of the wind generation in the target power system needs to be estimated. The proposed methodology to estimate the capacity credit of the wind generation in the power systems within the NEM is presented in the following Section.

\begin{tabular}{|c|l|c|c|c|c|}
\hline & \multicolumn{5}{|c|}{ Wind Generation } \\
\hline \multirow{3}{*}{$\underset{\Xi}{*}$} & & $S A$ & $T A S$ & $V I C$ & $N S W$ \\
\cline { 2 - 6 } & $S A$ & -0.016 & -0.0546 & -0.0261 & 0 \\
\cline { 2 - 6 } & $T A S$ & 0.1109 & 0.0384 & 0.1508 & 0.1237 \\
\cline { 2 - 6 } & $V I C$ & 0.0222 & -0.0463 & 0.0315 & 0.0468 \\
\cline { 2 - 6 } & $N S W$ & 0.0249 & -0.0765 & 0.0148 & 0.0429 \\
\cline { 2 - 6 } & $Q L D$ & -0.0505 & -0.1708 & -0.1008 & -0.0286 \\
\hline
\end{tabular}

Table 2: Demand and wind generation correlation coefficients between power systems.

\begin{tabular}{|l|c|c|c|c|c|}
\hline & SA & TAS & VIC & NSW & QLD \\
\hline SA & 1 & 0.4797 & 0.8657 & 0.7376 & 0.6082 \\
\hline TAS & 0.4797 & 1 & 0.6723 & 0.6905 & 0.5405 \\
\hline VIC & 0.8657 & 0.6723 & 1 & 0.8578 & 0.711 \\
\hline NSW & 0.7376 & 0.6905 & 0.8578 & 1 & 0.8265 \\
\hline QLD & 0.6082 & 0.5405 & 0.711 & 0.8265 & 1 \\
\hline
\end{tabular}

Table 3: Correlation coefficients between demands of power systems.

\section{Adequacy modelling of wind generation system in different power systems}

In the traditional multi-area adequacy analysis, the interconnections are modelled as a support from the neighbouring power systems during the generation deficiency in the generation system of the concerned power systems [3, $6,7]$. In [8], the interconnections are modelled to transmit shared capacity of jointly owned generators between multiarea power systems and the interconnections are assumed to be adequate for the study. Since the focus of this study is to estimate the capacity credit of wind generations due to diversity of demand and wind energy generation, the interconnections are modelled as the lines connected between the power system with wind generation and load centre of the target state owned power system where the wind power is transmitted. Hence the interconnections introduce capacity constraints for wind generation transfer and additional states in the availability model of the wind generation. The ELCC of the wind generation is used to estimate the capacity credit of the wind generation system in the generation adequacy of the target power system. 
The time series data of demand and the wind generations are used to capture the seasonal and diurnal coincidental variations between demand and wind generations in the adequacy estimation process. The inter-ties of each interconnection are modelled using a two state availability model of the lines. Since the variation of wind generation is modelled by the time series data, the available transferred wind generation is modelled for each time instance. The transferred wind generation capacity, $\mathrm{C}_{\mathrm{G}, \mathrm{i}, \mathrm{j}, \mathrm{s}}(\mathrm{t})$ from $\mathrm{i}^{\text {th }}$ power system to a different power system $\mathrm{j}$ for $\mathrm{s}^{\text {th }}$ available capacity state of tie line during $\mathrm{t}^{\text {th }}$ time instance is the minimum value between the available wind generation, $\mathrm{C}_{\mathrm{G}, \mathrm{i}}(\mathrm{t})$ at time instance $\mathrm{t}$ and available inter-tie capacity, $\mathrm{C}_{\mathrm{T}, \mathrm{i}, \mathrm{j}, \mathrm{s}}$ as shown in (1). The probability of the available transferred wind generation from $i^{\text {th }}$ power system to a different power system $\mathrm{j}, \mathrm{P}\left\{\mathrm{C}_{\mathrm{G}, \mathrm{i}, \mathrm{j}, \mathrm{s}}(\mathrm{t})\right\}$ at $\mathrm{t}^{\text {th }}$ time instance would be the probability of the available capacity of tie line, $\mathrm{P}\left\{\mathrm{C}_{\mathrm{T}, \mathrm{i}, \mathrm{j}, \mathrm{s}}\right\}$ as shown in (2).

$$
\begin{aligned}
& \mathrm{C}_{\mathrm{G}, \mathrm{i}, \mathrm{j}, \mathrm{s}}(\mathrm{t})=\min \left\{\mathrm{C}_{\mathrm{G}, \mathrm{i}}(\mathrm{t}), \mathrm{C}_{\mathrm{T}, \mathrm{i}, \mathrm{j}, \mathrm{s}}\right\} \\
& \mathrm{P}\left\{\mathrm{C}_{\mathrm{G}, \mathrm{i}, \mathrm{j}, \mathrm{s}}(\mathrm{t})\right\}=\mathrm{P}\left\{\mathrm{C}_{\mathrm{T}, \mathrm{i}, \mathrm{j}, \mathrm{s}}\right\}
\end{aligned}
$$

The available capacity $\mathrm{C}_{\mathrm{T}, \mathrm{i}, \mathrm{j}, \mathrm{s}}$ of tie line and corresponding probability $\mathrm{P}\left\{\mathrm{C}_{\mathrm{T}, \mathrm{i}, \mathrm{j}, \mathrm{s}}\right\}$ can be evaluated using the similar procedures of evaluating capacity outage probability table (COPT) of conventional generation systems as presented in [2]. If there are one or more power systems between the power system with wind generation and target power system, the interconnections are considered to be connected in series. The available capacity, $\mathrm{C}_{\mathrm{T}, \mathrm{i}, \mathrm{j}, \mathrm{s}}$ of the tie lines between power system $\mathrm{i}$ and $\mathrm{j}$ for $\mathrm{s}^{\text {th }}$ state is the minimum among the capacities of the tie lines in series as shown in (3). The probability of the available capacity of the interconnection, $\mathrm{P}\left\{\mathrm{C}_{\mathrm{T}, \mathrm{i}, \mathrm{j}, \mathrm{s}}\right\}$ is evaluated using (4). $\mathrm{P}_{1}\left\{\mathrm{C}_{\mathrm{T}, \mathrm{i}, \mathrm{j}, \mathrm{s}}\right\}$ is the probability of $\mathrm{i}^{\text {th }}$ tie line in series with available capacity $\mathrm{C}_{\mathrm{T}, \mathrm{i}, \mathrm{j}, \mathrm{s}}$ and $\mathrm{P}_{\mathrm{m}}\left\{\mathrm{C}_{\mathrm{T}, \mathrm{i}, \mathrm{j}, \mathrm{s}}\right\}$ is the probability of the $\mathrm{m}^{\text {th }}$ tie line in series with available capacity greater than $\mathrm{C}_{\mathrm{T}, \mathrm{i}, \mathrm{j}, \mathrm{s}}$.

$$
\begin{aligned}
& \mathrm{C}_{\mathrm{T}, \mathrm{i}, \mathrm{j}, \mathrm{s}}=\min \left\{\mathrm{C}_{\mathrm{T}, \mathrm{i}, 1, \mathrm{~s}}, \ldots, \mathrm{C}_{\mathrm{T}, \mathrm{n}, \mathrm{j}, \mathrm{s}}\right\} \\
& \mathrm{P}\left\{\mathrm{C}_{\mathrm{T}, \mathrm{i}, \mathrm{j}, \mathrm{s}}\right\}=\Sigma_{1}\left[\mathrm{P}_{1}\left\{\mathrm{C}_{\mathrm{T}, \mathrm{i}, \mathrm{j}, \mathrm{s}}\right\} \times \prod_{\mathrm{m}} \mathrm{P}_{\mathrm{m}}\left\{\mathrm{C}_{\mathrm{T}, \mathrm{i}, \mathrm{m}, \mathrm{s}} \geq \mathrm{C}_{\mathrm{T}, \mathrm{i}, \mathrm{j}, \mathrm{s}}\right\}\right]
\end{aligned}
$$

The total COPT of the target power system for $\mathrm{t}^{\text {th }}$ time instance is formed using the convolution between the interconnection capacities at $\mathrm{t}^{\text {th }}$ instance and COPT of the conventional generation plants in the target power system. Hence the loss of load expectation (LOLE) of the target power system is estimated and a decrease in the system LOLE is observed due to increase in generation capacity. The load of the target system is then increased uniformly for the entire time period until the system LOLE becomes equal to previous level. The ELCC of the wind generation in the target power system is then estimated as the additional load that returns the system LOLE to the previous level.

\section{Generation planning framework for sharing wind resources}

The capacity credit of each existing wind generation in the power systems connected to the NEM power grid is estimated using the proposed method illustrated in the previous section and the results are presented in Table 4. It can be observed that the capacity credit of the wind generations in South
Australia (SA), Tasmania (TAS) and Victoria (VIC) have higher capacity credits in the New South Wales (NSW) power system than the capacity credits in their own power systems. In particular, wind generation in SA has a higher potential in terms of capacity credit in the power systems of NSW and VIC.

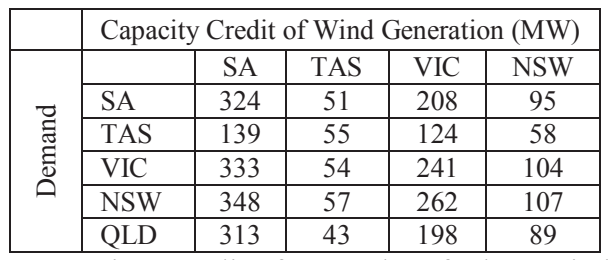

Table 4: Capacity credit for each of the existing wind generation in the other power systems of NEM power grid.

Since the different states have different wind installed capacities, it is difficult to decide which wind generation has better capacity credit potential in a particular state. For this purpose the installed capacity of wind generation in each power system is scaled to $480 \mathrm{MW}$ which is the highest capacity that can be transferred through any interconnectors without exceeding the limit/violating the constraints among the interconnector capacities. The capacity credits are estimated for the $480 \mathrm{MW}$ wind generation system in each of the other power systems, and results are presented in Table 5. The most potential state that has a high capacity credit of wind generation can be selected from Table 5. For example in QLD power system, the highest capacity credit can be received by the NSW wind generation followed by SA wind generation. Since QLD is not rich in wind resource and contrariwise SA has high wind potential locations, QLD can import wind generation from SA to meet the RET.

\begin{tabular}{|c|l|c|c|c|c|}
\hline & \multicolumn{5}{|c|}{ Capacity Credit of Wind Generation (MW) } \\
\hline \multirow{4}{*}{$\mathcal{Z}$} & & SA & TAS & VIC & NSW \\
\cline { 2 - 6 } & SA & 138 & 154 & 126 & 154 \\
\cline { 2 - 6 } & TAS & 104 & 91 & 98 & 71 \\
\cline { 2 - 6 } & VIC & 160 & 171 & 144 & 188 \\
\cline { 2 - 6 } & NSW & 158 & 179 & 154 & 189 \\
\cline { 2 - 6 } & QLD & 137 & 124 & 120 & 147 \\
\hline
\end{tabular}

Table 5: Capacity credit for each $480 \mathrm{MW}$ wind generation in each of the other power systems of NEM power grid.

The incremental capacity credit of the wind generation is likely to reduce as the installed capacity of the wind generation increases. The capacity credits of SA wind generation for different installed capacities within SA power system are shown by the solid line in Figure 2. It is found that for the first $1500 \mathrm{MW}$ of installed capacity, the wind generation receives capacity credit of $355 \mathrm{MW}$ from the SA power system. For the additional $1500 \mathrm{MW}$ of installed capacity, the wind generation receives only capacity credit of $240 \mathrm{MW}$ from the SA power system. Hence the additional 1500 MW wind generation is not receiving proportional capacity credit benefit.

The capacity credits of wind generation in SA with various installed capacities which are dedicatedly transmitted to QLD are also shown in Figure 2 by the dotted line. It is found that the incremental capacity credit received by the SA wind generation from QLD power system starts to reduce after 550 
MW of installed capacity. This is because of the capacity transmission constraint imposed by the interconnections between SA and VIC. If the additional $1500 \mathrm{MW}$ of SA wind generation is dedicated for transmitting to QLD through the interconnections and transmission system of VIC and NSW, this can receive a capacity credit of 334 MW from the QLD power system. Hence the total capacity credit received by the $3000 \mathrm{MW}$ wind generation in SA from the SA and QLD power systems is $689 \mathrm{MW}$ which is $15.8 \%$ higher than that received from the SA power system alone. The various total capacity credits received by the SA wind generation from SA power system for the first $1500 \mathrm{MW}$ installed capacity and from QLD power system for additional dedicated installed SA wind generation capacities are plotted in Figure 3.

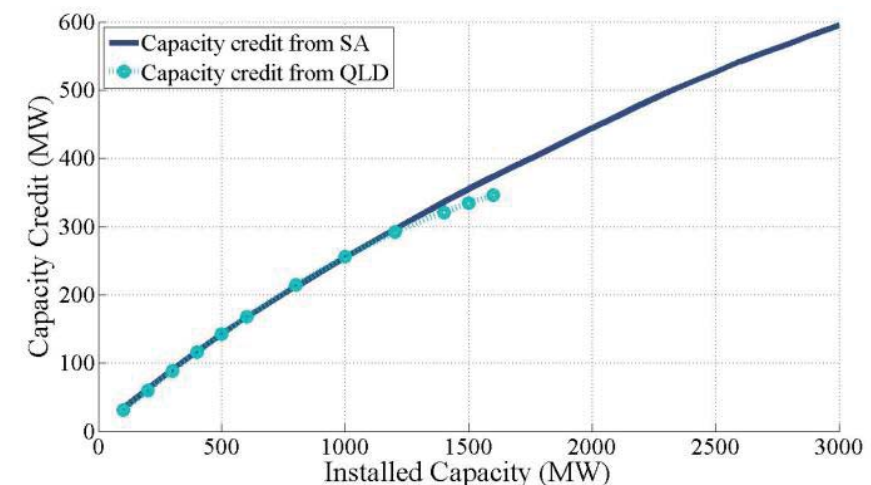

Figure 2: Capacity credit of SA wind generation in SA and QLD power systems.

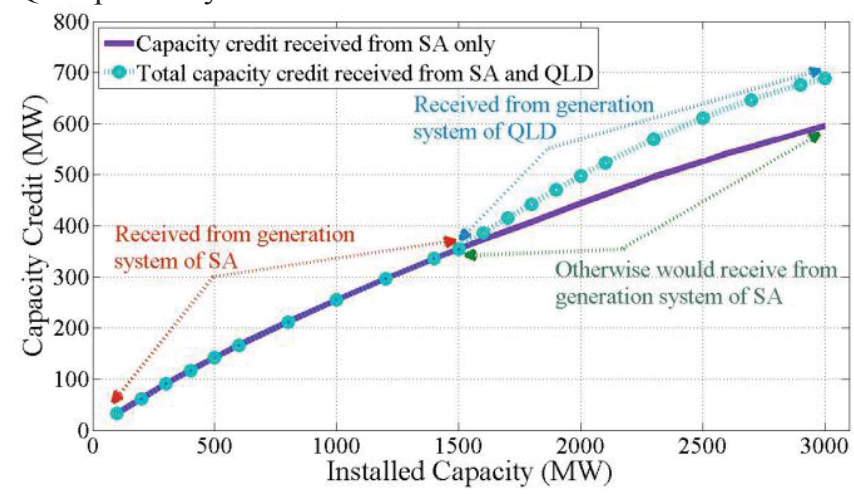

Figure 3: Total capacity credit of SA wind generation in SA and QLD power systems.

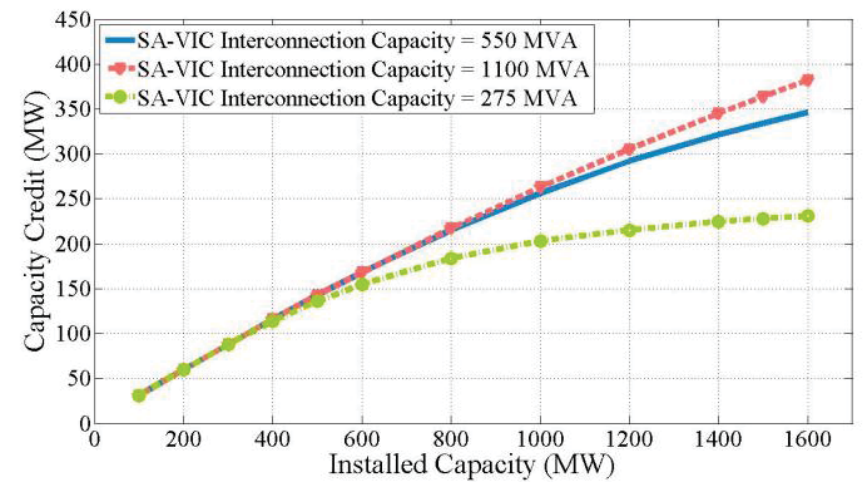

Figure 4: Capacity credit of SA wind generation in QLD power system for different interconnection capacities between SA and VIC.
The capacity of the interconnection plays an important role in the capacity credit of wind generation in a power system for transmitting power to another power system through interconnections. The impact of different interconnections capacities between SA and VIC on the capacity credits of the SA wind generation received from the QLD power system is shown in Figure 4. It is found that the lower interconnection capacity reduces the capacity credit significantly with respect to the existing interconnection capacity.

\section{Conclusion}

This paper presents a capacity credit estimation method for wind generation in power systems located within the interconnected Southeast Australian power grid, where a framework has been proposed for wind generation planning by sharing the wind energy resource diversity among the power systems through existing interconnections. A probabilistic adequacy model has been developed to estimate the capacity credit of the wind generation plants in a power system which is connected to other power systems with wind generation through inter-ties. The probabilistic adequacy model is then applied to estimate the capacity credit of wind generation plant in the power systems of different states which are interconnected in the Southeast Australian power grid. Also, the impact of the inter-tie ratings and varying wind penetration on the capacity credit of the wind generation plants are investigated.

\section{References}

[1] Australian Energy Market Operators (AEMO). Website. available online: www.aemo.com.au

[2] R. Billinton, R. N. Allan. Reliability Evaluation of Power Systems, Second edition, Plenum Press, NY (1996).

[3] R. K. Deb. "Effective load carrying capability of interties", IEEE transactions on Power Apparatus and Systems, Vol. PAS-103, pp. 3480-3487, (1984).

[4] Department of Resource, Energy and Tourism. "Energy white paper 2012: Australia's energy transformation”, report, (2012).

[5] C. Loutan, D. Hawkins, "Integration of Renewable Resources", California ISO report, November 2007.

[6] N. S. Rau, C. Necsulescu, K. F. Schenk, R. B. Misra. "Reliability of interconnected power systems with correlate demands", IEEE transactions on Power Apparatus and Systems, Vol. PAS-101, pp. 3421-3430, (1982).

[7] K. F. Schenk, Q. Ahsan, S. Vassos. "The segmentation method applied to the evaluation of loss of load probability of two interconnected systems", IEEE transactions on Power Apparatus and Systems, Vol. PAS-103, pp. 1537-1541, (1984).

[8] C. Singh, N. Gubbala. "Reliability evaluation of interconnected power systems including jointly owned generators", IEEE transactions on Power Systems, Vol. 9, pp. 404-412, (1994). 